Western University

Scholarship@Western

2-1-1996

\title{
Faster femoral artery blood velocity kinetics at the onset of exercise following short-term training.
}

J K Shoemaker

kshoemak@uwo.ca

S M Phillips

H J Green

R L Hughson

Follow this and additional works at: https://ir.lib.uwo.ca/kinpub

Part of the Kinesiology Commons

\section{Citation of this paper:}

Shoemaker, J K; Phillips, S M; Green, H J; and Hughson, R L, "Faster femoral artery blood velocity kinetics at the onset of exercise following short-term training." (1996). Kinesiology Publications. 36.

https://ir.lib.uwo.ca/kinpub/36 


\title{
Faster femoral artery blood velocity kinetics at the onset of exercise following short-term training
}

\author{
J.K. Shoemaker, S.M. Phillips, H.J. Green, R.L. Hughson * \\ Department of Kinesiology, University of Waterloo, Waterloo, Ont. N2L 3G1, Canada
}

Reccived 31 March 1995; accepted 13 September 1995

\begin{abstract}
Objective: The hypothesis that the adaptation to endurance exercise training included a faster increase in blood flow at the onset of exercise was tested in 12 healthy young men who endurance-trained (ET) $2 \mathrm{~h} /$ day, for 10 days at $65 \%$ VO $\mathrm{O}_{2}$ peak on a cycle ergometer, and in 11 non-training control $(C)$ subjects. Methods: Blood flow was estimated from changes in femoral artery mean blood velocity (MBV) by pulsed Doppler. Beat-by-beat changes in cardiac output (CO) and mean arterial pressure (MAP) were obtained by impedance cardiography and a Finapres finger cuff, respectively. MBV, MAP and CO were measured at rest and during 5 min of dynamic knee extension exercise. Both legs worked alternately with $2 \mathrm{~s}$ raising and lowering a weight (15\% maximal voluntary contraction) followed by $2 \mathrm{~s}$ rest while the other leg raised and lowered the weight. Results: In the ET group the time to 63\% ( $\mathrm{T}_{63 \%}$ ) of the approximately exponential increase in MBV following 10 days of training $(8.6 \pm 1.2 \mathrm{~s}$, mean \pm s.e.) was significantly faster than the Day 0 response $(14.2 \pm 2.1 \mathrm{~s}, P<0.05)$. The $\mathrm{T}_{63 \%}$ of femoral artery vascular conductance $\left(\mathrm{VC}_{\mathrm{fa}}\right)$ was also faster following 10 days of ET $(9.4 \pm 0.9 \mathrm{~s})$ versus Day $0(16.0 \pm 2.5 \mathrm{~s})(0.05)$. There was no change in the $\mathrm{T}_{63 \%}$ of both $\mathrm{MBV}$ and $\mathrm{VC}_{\mathrm{fa}}$ for the $\mathrm{C}$ group. The kinetics of $\mathrm{CO}$ were not significantly affected by ET, but the amplitude of $\mathrm{CO}$ in the adaptive phase, and at steady state, were significantly greater $(P<0.05)$ at Day 10 compared to Day 0 for the ET group with no change in the $C$ group. Conclusions: These data supported the hypothesis that endurance training resulted in faster adaptation of blood flow to exercising muscle, and further showed that this response occurred early in the training program.
\end{abstract}

Keywords: Blood flow; Cardiac output; Exercise; Vascular conductance; Human

\section{Introduction}

Endurance training is associated with improvements in oxygen transport due to larger cardiac stroke volumes [1] and higher capillary density [2] within the trained muscle. Whereas the increase in capillary density appears to require prolonged training [2], improvements in the functional vasodilation of arterioles in rats [3] and in cardiac performance in humans [4] have been observed with 6-12 days of training.

Although it has been well established that the aerobic metabolic system adapts more rapidly to the demands of constant load exercise following a training period [5], neither the duration of training required nor the mechanism

\footnotetext{
"Corresponding author. Tel: (+1-519) 888-4567, ext. 2516; fax: (+ I-519) 746-6776; e-mail; hughson@cgsa.uwaterloo.ca.
}

has been established. Perhaps the faster increase in oxygen uptake $\left(\dot{\mathrm{VO}}_{2}\right)$ is a function of a more rapid increase in total cardiac output and blood flow to the active muscles. Adaptations to the kinetics of muscle blood flow following training have not been investigated.

In the present study we have used pulsed Doppler ultrasound to obtain beat-by-beat measures of femoral artery mean blood velocity (MBV), an estimate of blood flow [6], during dynamic knee extension exercise (KE) to test the hypothesis that 10 days of cycle ergometer endurance training will produce faster blood flow responses to the active limbs in exercising man. These responses were quantified by fitting the time course data to exponential models which provided information regarding the kinetics of the MBV response. Cardiac output (CO) and

Time for primary review 39 days. 
mean arterial pressure (MAP) were also measured to provide insight into the mechanism(s) that might regulate a more rapid increase in MBV after ET.

\section{Methods}

\subsection{Subjects}

Two groups of active, but untrained, healthy men volunteered for the study. One group performed endurance training (ET) $(n=12)$ and the other acted as a control (C) $(n=11)$. The volunteers indicated that they were free of any form of cardiovascular or musculoskeletal disease, and none was currently on any medications as assessed by a medical history. The average ( \pm standard deviation) physical characteristics of the subjects are described in Table 1. Although the participants were not randomly assigned to the experimental and control groups, care was taken to insure that they were similar in physical and physiologic characteristics. After receiving a complete description of the experimental protocol and potential risks, each subject provided signed consent to the testing procedures on a form approved by the Office of Human Research at the University.

\subsection{Experimental apparatus and exercise protocol}

The experiment required that subjects perform knee extension (KE) exercise in a seated position with the hips extended to $\sim 120^{\circ}$. In addition to instructions to remain as still as possible during the testing procedure, body motion was further minimized by strapping the subject to the chair with one belt placed under the axilla and another strapped across the anterior superior iliac spines. The latter strap was modified so that pressure was placed evenly on the anterior superior iliac spines allowing unimpeded blood flow through the femoral artery. After $10 \mathrm{~min}$ of seated rest a $1 \mathrm{ml}$ blood sample was collected by venipuncture of an antecubital fossa vein for the determination of haematocrit. The haematocrit values were used to correct calculated stroke volumes determined by impedance cardiogra-

Table 1

Subject characteristics, $\dot{\mathrm{V}}_{2}$ peak and haematocrit $(\mathrm{Hct})$

\begin{tabular}{lll}
\hline & ET $(n=12)$ & $C(n=11)$ \\
\hline Age (yr) & $23.2 \pm 1.0$ & $27.2 \pm 0.3$ \\
Height $(\mathrm{cm})$ & $176 \pm 4$ & $176 \pm 3$ \\
Weight $(\mathrm{kg})$ & $76.2 \pm 2.8$ & $75.4 \pm 2.0$ \\
$\dot{\mathrm{VO}}_{2}$ peak(1/min) (Day 0) & $3.47 \pm .14$ & $3.37 \pm 0.10$ \\
$\dot{\mathrm{VO}}_{2}$ peak(1/min) (Day 10) & $3.57 \pm 0.14^{*}$ & $3.32 \pm 0.10$ \\
$\mathrm{Hct}(\%)($ Day 0) & $45.0 \pm 0.7$ & $44.9 \pm 0.7$ \\
Hct (\%) (Day 10) & $43.4 \pm 1.0$ & $44.7 \pm 1.0$ \\
\hline
\end{tabular}

Values are mean \pm s.d. ET $=$ endurance-trained group; $\mathrm{C}=$ control group. "Significantly different from pre-training $\dot{\mathrm{VO}}_{2 \text { peak }}(P<0.05)$. phy (see below). Following $\sim 20 \mathrm{~min}$ of seated rest the first trial began. In each experimental session the subjects performed four $\mathrm{KE}$ trials each of which consisted of $1 \mathrm{~min}$ rest followed by $5 \mathrm{~min} \mathrm{KE}$ exercise. At least $5 \mathrm{~min}$ of rest occurred between each trial. To diminish the effects of anticipation on the cardiovascular responses the subjects were not aware of the time in any trial; they were simply told when to begin and to end the exercise.

Knee extension exercise involved lifting and lowering a weight equivalent to $15 \%$ of each subject's predetermined maximal voluntary isometric contraction (MVC). The weights used ranged between 8 and $12 \mathrm{~kg}$ and were fixed to the ankle by a cable and pulley mechanism. The exercise was performed through $35^{\circ}$ of knee extension $\left(\sim 100^{\circ}\right.$ to $\sim 135^{\circ}$ ) using a $50 \%$ duty cycle where $2 \mathrm{~s}$ of active extension and flexion was followed by $2 \mathrm{~s}$ of rest; therefore, 15 contraction cycles were produced each minute by each leg in an alternating pattern so that while one leg was extending and flexing, the other was relaxing. A timed light signal provided the subjects with a constant exercise cadence. Previous pilot work in our laboratory, and work by Walløe and Wesche [7], have shown this cadence to be adequate for maximizing exercise blood flow while minimizing the post-exercise hyperaemia.

During the $\mathrm{KE}$ sessions, subjects were advised, and periodically reminded, of the need to fully relax the quadriceps muscle group of the non-working leg. Auditory feedback of the MBV signal was provided and the subjects were coached according to the type of sounds indicative of both relaxed and contracted muscle.

As much as possible, each subject was tested at the same time of day and all subjects were advised to maintain equivalent conditions of diet and rest on the day of, and the day prior to, each testing session. In addition, all subjects abstained from caffeine for $24 \mathrm{~h}$, and did not eat for $3 \mathrm{~h}$ prior to each test.

\subsection{Experimental design}

The ET group performed cycle ergometer training for 2 $\mathrm{h} /$ day, 4-5 days/wk for a total of 8-10 training days. Training intensity was set at $65 \% \mathrm{VO}_{2 \text { peak }}$. The $\mathrm{C}$ group maintained their levels of activity required for daily functions but did not perform any endurance training. The $\mathrm{KE}$ tests for both groups were performed prior to the commencement of training (Day 0 ) and after 10 days (Day 10 ).

\subsection{Data acquisition}

Femoral artery MBV was determined from the spectra of a pulsed-Doppler ultrasound signal (model $500 \mathrm{~V}$, Multigon Industries, Inc., Mt. Vernon, NY). A flat probe with an operating frequency of $4 \mathrm{MHz}$ was fixed to the skin over the common femoral artery $2-3 \mathrm{~cm}$ distal to the inguinal ligament. This position eliminated the contribution of blood flow directed to the abdominal muscles 
which would occur if the probe was placed proximal to the inguinal ligament. The angle of the transducer crystal relative to the skin was $45^{\circ}$ and the ultrasound gate was maintained at full width to facilitate insonation of the total width of the artery with approximately constant intensity. With this apparatus we were able to maintain a clear Doppler signal both at rest and during the KE exercise. The Doppler shift frequency spectra were processed by a quadrature audio demodulator [8] which provided the instantaneous mean blood velocity in real time allowing collection of $\mathrm{MBV}$ in $\mathrm{A} / \mathrm{D}$ units. The quadrature audio demodulator also generated the appropriate Doppler shift frequency signals to produce a two-point calibration. Beatby-beat MBV was calculated by integrating the total area under the instantaneous MBV profile using the marked QRS complex of the ECG tracing to signal the end of one heart beat and the beginning of the next.

Mean arterial pressure was obtained by using a pneumatic finger cuff (Ohmeda 2300, Finapres, Englewood, $\mathrm{CO})$ [9]. The arm and hand from which blood pressure data were collected were supported at heart level.

An estimate of femoral artery vascular conductance $\left(\mathrm{VC}_{\mathrm{fa}_{\mathrm{a}}}\right)$ was calculated as the quotient of MBV/MAP [10]. This estimate of vascular conductance includes the assumption that $\mathrm{MBV}$ is directly and linearly related to arterial blood flow.

The increase in blood flow to the active limb may be related to the rate, or magnitude, of change in cardiac output. Stroke volume was monitored beat-by-beat using impedance cardiography (Minnesota Impedance Cardiograph, Model 304-B, Surcom, Minneapolis, MN). Four pairs of spot electrodes were placed about the neck and about the chest according to standard placement [11]. A software program marked the $\mathrm{d} Z / \mathrm{d} t$, and stroke volume was calculated for each heart beat with corrections to blood resistivity based on haematocrit values taken in each experimental session [12]. From the measured values of $\mathrm{CO}$ and MAP, the systemic vascular conductance was calculated as CO/MAP on a beat-by-beat basis.

The mean impedance $\left(Z_{0}\right)$, the rate of change of impedance $(\mathrm{d} Z / \mathrm{d} t)$, the electrocardiogram, and the mean blood velocity signals were all recorded at a frequency of $200 \mathrm{~Hz}$ on a microcomputer data acquisition system. These data were collected continuously for each 6 min trial. The raw MBV and impedance data were smoothed using a five heartbeat moving average procedure after which further analysis occurred.

\subsection{Data analysis: kinetic parameters}

The mean resting MBV was not different over four repeated trials separated by $5 \mathrm{~min}$. Therefore, the random noise component of beat-by-beat measures was reduced by ensemble averaging the MBV, MAP, and CO data collected from all four trials at both the Day 0 and Day 10 times to produce a single data set for each subject on each test day. In this procedure, the data for the files to be averaged are time-aligned and values from each trial for a given $1 \mathrm{~s}$ time span are averaged.

In order to quantify and compare the time courses of $\mathrm{MBV}, \mathrm{VC}_{\mathrm{fa}}$ and $\mathrm{CO}$ responses with training, exponential curves were fitted to the time series data from the averaged data set. Inspection of the raw data suggested that both $\mathrm{MBV}$ and $\mathrm{VC}_{\mathrm{fa}}$ responded as either a two- or three-component exponential; following the onset of exercise the early initial rise (first component) was followed by a plateau between $\sim 10$ and $20 \mathrm{~s}$ which gave way to a further rise (second component) towards a steady-state level which sometimes occurred as an overshoot pattern (third component). An example of these responses, and the modelled prediction of the data, is provided in Fig. 1. In contrast, the $\mathrm{CO}$ responses to exercise rose with either a one- or a two-component exponential pattern.

The MBV response was modelled as a two-component exponential unless an overshoot (with the resultant pattern in the residuals) was found. In Day 0 testing 3 of 12 ET and 5 of $11 \mathrm{C}$ subjects required a three-component model. After 10 days, 8 of $12 \mathrm{ET}$ and 4 of $11 \mathrm{C}$ subjects required a three-component model to account for the overshoot in $\mathrm{MBV}$. A similar pattern resulted for the $\mathrm{VC}_{\mathrm{fa}}$ data. Here, a two-component model was used for all Day 0 curves for both ET and $\mathrm{C}$ groups whereas a three-component exponential was required for 6 ET subjects compared to one C group subject on Day 10. None of the $C O$ responses required the more complex fitting procedure and were adequately modelled through either a one- or a two-component exponential curve.

The three-component model equation, which incorporates the one- and two-component models, is the following:

$$
\begin{aligned}
y= & y_{b l}+\mathrm{AMP}_{1} \cdot\left(1-\mathrm{e}^{-\left(t-\mathrm{TD}_{1}\right) / \tau_{1}}\right) \\
& +\mathrm{AMP}_{2} \cdot\left(1-\mathrm{e}^{-\left(t-\mathrm{TD}_{2}\right) / \tau_{2}}\right)+\mathrm{AMP}_{3} \\
& \cdot\left(1-\mathrm{e}^{-\left(t-\mathrm{TD}_{3}\right) / \tau_{3}}\right)
\end{aligned}
$$

where $y_{b l}$ is the baseline resting value, $\mathrm{TD}_{1}$ and $\mathrm{TD}_{2}$ are the time delays from the onset of exercise to the onset of the responses of the first and second component, respectively; $\mathrm{AMP}_{1}$ is the change in $y$ above $y_{b l}$ in the first component whereas $\mathrm{AMP}_{2}$ and $\mathrm{AMP}_{3}$ represent the change in $y$ for times after $\mathrm{TD}_{2}$ to a predicted steady-state level; $\tau_{1}, \tau_{2}$, and $\tau_{3}$ represent the time constants for each component. In these models $\mathrm{TD}_{1}$ was constrained to be greater than, or equal to, zero and, if the three-component model was used, $\mathrm{TD}_{2}=\mathrm{TD}_{3}$. Therefore, the best-fit curves and the associated time constants and time delays were calculated for each of $\mathrm{MBV}, \mathrm{VC}_{\mathrm{fa}}$ and $\mathrm{CO}$ as described by Hughson et al. [13]. From these parameters the time to $63 \%$ of the increase in the variable under investigation $\left(\mathrm{T}_{63 \%}\right)$, equivalent to mean response time, was calculated as:

$T_{63 \%}=\frac{\mathrm{AMP}_{1}}{\mathrm{AMP}_{1}+\mathrm{AMP}_{2}+\mathrm{AMP}_{3}} \cdot\left(\tau_{1}+\mathrm{TD}_{1}\right)$ 


$$
\begin{aligned}
& +\frac{\mathrm{AMP}_{2}}{\mathrm{AMP}_{1}+\mathrm{AMP}_{2}+\mathrm{AMP}_{3}} \cdot\left(\tau_{2}+\mathrm{TD}_{2}\right) \\
& +\frac{\mathrm{AMP}_{3}}{\mathrm{AMP}_{1}+\mathrm{AMP}_{2}+\mathrm{AMP}_{3}} \cdot\left(\tau_{3}+\mathrm{TD}_{3}\right)
\end{aligned}
$$

To corroborate the findings of the kinetic analysis, the amplitude of the MBV response during the on-transient phase of exercise was determined at the $10 \mathrm{~s}$ point of exercise for the ET group.

\subsection{Statistical Analysis}

The effects of short-term training on $\mathrm{MBV}, \mathrm{VC}_{\mathrm{fa}}$ and $\mathrm{CO}$ responses were analyzed by a repeated measures analysis of variance. The general linear model (SAS Institute Inc. Cory, NC) model was used due to the unbalanced group sizes. Initially, a two-way repeated measures ANOVA was employed with endurance training (ET) and control (C) as the between-subjects factor and days of training as the within-subjects factor. The steady-state baseline (Rest), increase (AMP), and mean response time $\left(T_{63 \%}\right)$ values were the dependent variables. The relatively large between-subject variance precluded detection of between-group statistical significance. However, within the ET group, the effect of training was evident when analysed with a repeated measures one-way ANOVA procedure. Similarly, a one-way ANOVA with repeated measures was used to test the effect of training on $\mathrm{VO}_{2 \text { peak }}$. In all tests, the level of significance was set at $P<0.05$ and any differences were further analyzed with the Student-Neumann-Keuls post hoc test. All data are presented as mean \pm standard deviation (s.d.).

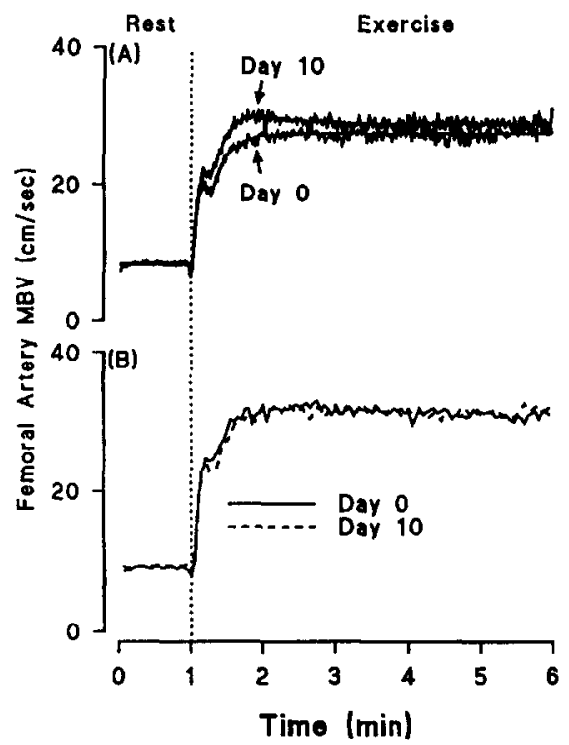

\section{Results}

\subsection{Heart rate}

Ten days of training resulted in a reduction in both resting (71.6 \pm 6.31 versus $67.3 \pm 6.2 \mathrm{~b} / \mathrm{min}$, Day 0 versus Day $10 ; P<0.05)$ and exercise $(90.3 \pm 6.5$ versus $84.1 \pm 6.61 \mathrm{~b} / \mathrm{min}$, Day 0 versus Day $10 ; P<0.05$ ) heart rates. In contrast, no change in heart rate occurred for the Control group at rest $(70.8 \pm 5.5$ versus $72.7 \pm 8.4 \mathrm{~b} / \mathrm{min}$, Day 0 versus Day $10 ; P>0.05)$ or during exercise $(90.4$ \pm 8.6 versus $88.4 \pm 9.8 \mathrm{~b} / \mathrm{min}$, Day 0 versus Day 10; $P>0.05)$.

\subsection{Mean blood velocity and femoral artery vascular conductance kinetics}

The increase in both MBV and $\mathrm{VC}_{\mathrm{fa}}$ was rapid following the onset of exercise (Fig. 1 and Table 2). For the control (C) group, there were no differences in the rate of increase $\left(T_{63 \%}\right)$ nor the steady-state exercise amplitude in either MBV or $\mathrm{VC}_{\mathrm{fa}}$ between the Day 0 and Day 10 test sessions (Table 2). Similarly, there was no change in the steady-state exercise amplitude of the increase after training for the exercise-trained (ET) group, but the rate of increase $\left(T_{63 \%}\right)$ for each of $\mathrm{MBV}$ and $\mathrm{VC}_{\mathrm{fa}}$ was faster for Day 10 than Day $0(P<0.05$, Table 2). Further, MBV amplitudes for the ET group at $10 \mathrm{~s}$ following the onset of exercise were greater following training $(14.1 \pm 7.3 \mathrm{~cm} / \mathrm{s})$ compared with Day $0(12.2 \pm 7.6)(P<0.05)$. No differences in MBV amplitudes during the on-transient phase for the $\mathrm{C}$ group were observed. There were no differences in

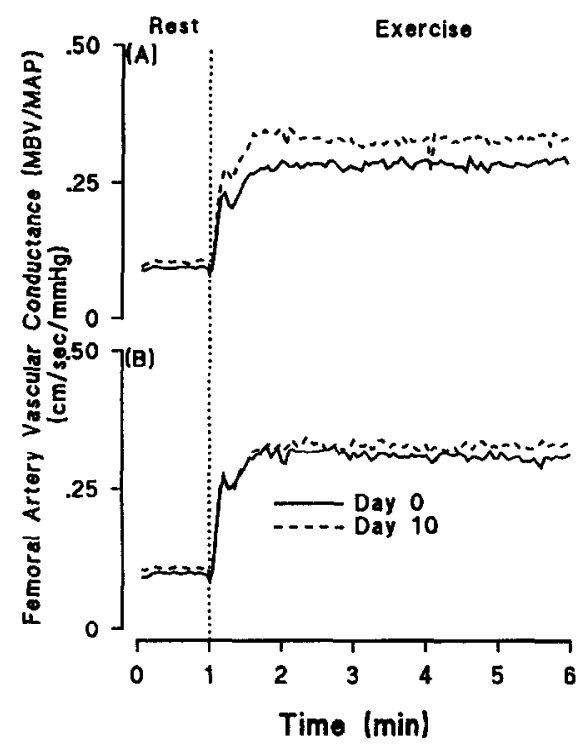

Fig. 1. The rate of increase in femoral artery mean blood velocity (left side) and vascular conductance (MBV/MAP) (right side) is faster following 10 days of $2 \mathrm{~h}$ /day endurance training (A) $(n=12)$ compared with no effect of test day in the control group (B) $(n=11)$. The data represent the average of all endurance-trained or control subjects performing 4 trials each on each test day. All beat-by-beat MBV data points are plotted for the ET group (A) with the modelled exponential curves overlaid on both the Day 0 and Day 10 responses. The average of three data points is displayed in the MBV (B) and the $\mathrm{VC}_{\mathrm{fa}}$ plots. 
Table 2

Effects of short-term training on the resting (Rest), amplitude of increase at $5 \mathrm{~min}$ of exercise (Amp), and the time to $63 \%$ ( $T_{63 \%}$ ) of the increase in $\mathrm{MBV} / \mathrm{MAP}\left(\mathrm{VC}_{\mathrm{fa}}\right), \mathrm{MBV}$ and $\mathrm{CO}$ responses to knee extension exercise

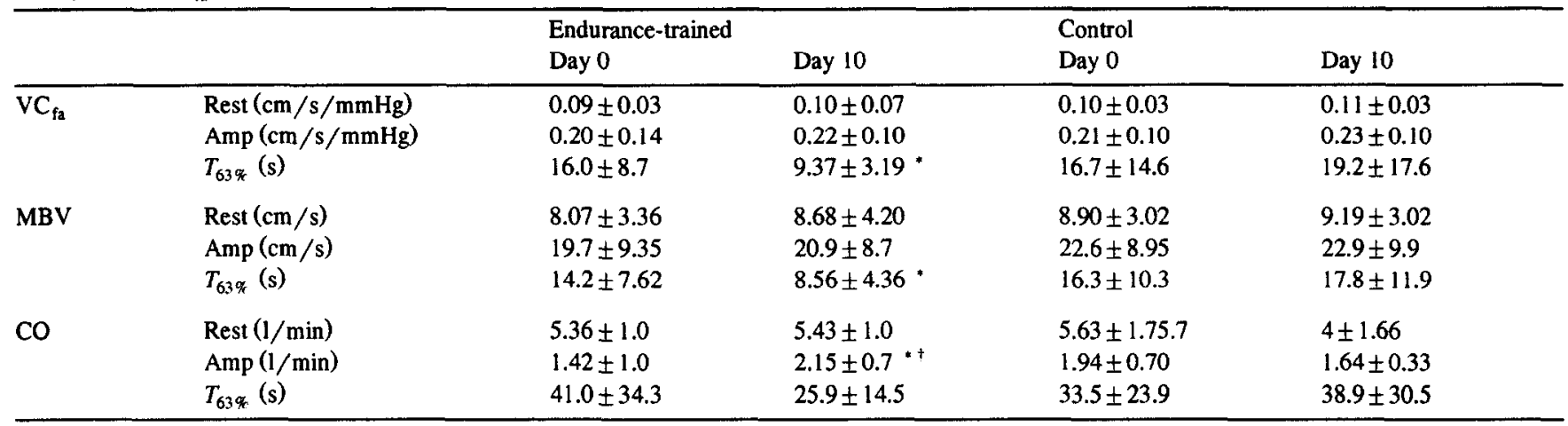

Values are mean \pm s.d. $\mathrm{MBV}=$ mean blood velocity; $\mathrm{MAP}=$ mean arterial pressure; $\mathrm{VC}_{\mathrm{fa}}=$ stimated femoral artery vascular conductance; $\mathrm{CO}=$ cardiac output. " Significantly different from Day $0(P<0.05) .{ }^{\dagger}$ Significantly different from control, Day 10.

the steady-state exercise amplitudes of either MBV or $\mathrm{VC}_{\mathrm{fa}}$ between the $\mathrm{C}$ and $\mathrm{ET}$ groups.

\subsection{Mean arterial pressure}

From rest to exercise, there were small, non-significant, changes in MAP that were unaffected by training. For the $\mathrm{C}$ group, the respective rest and steady-state exercise MAP values of $93.1 \pm 8.3$ and $105 \pm 15 \mathrm{mmHg}$ on Day 0 were greater than $85.7 \pm 5.3$ and $95.0 \pm 7.3 \mathrm{mmHg}$ on Day 10 $(P<0.05)$. Corresponding values for the ET group were $88.4 \pm 6.6$ and $95.1 \pm 9.4 \mathrm{mmHg}$ on Day 0 , and $86.4 \pm 6.6$ and $92.4 \pm 8.0 \mathrm{mmHg}$ on Day 10 .

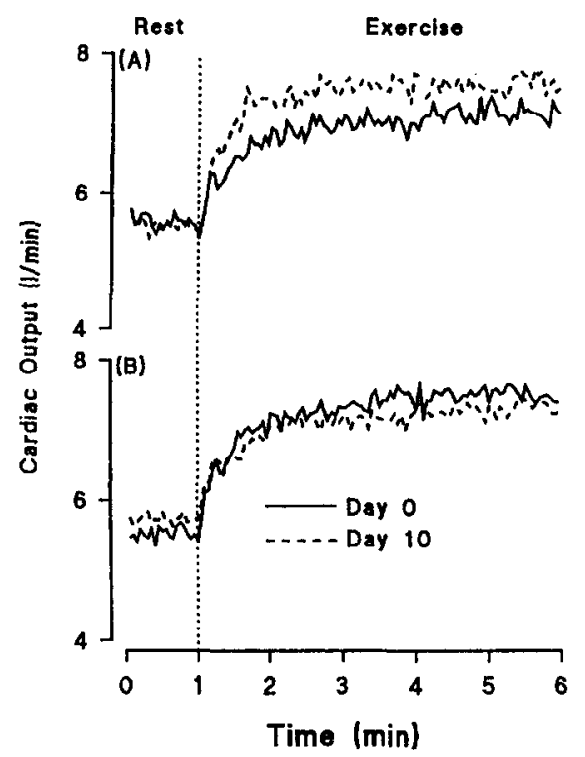

\subsection{Cardiac output and systemic vascular conductance kinetics}

The increase in $\mathrm{CO}$ following the onset of exercise was a slower response than the changes in $\mathrm{MBV}$ and $\mathrm{VC}_{\mathrm{fa}}$ (Fig. 2 and Table 2). For the $C$ group, there were no changes in $T_{63 \%}$ or amplitude from Day 0 to Day 10 . Although $T_{63 \%}$ appeared to be faster on Day 10 than Day 0 for the ET group, this was not significant (Table 2). Because the steady-state exercise amplitude of $\mathrm{CO}$ was, first of all, significantly greater on Day 10 than on Day 0 in the ET group, and secondly, greater in the ET group compared with $C$ on Day $10(P<0.05$, Table 2), we decided to

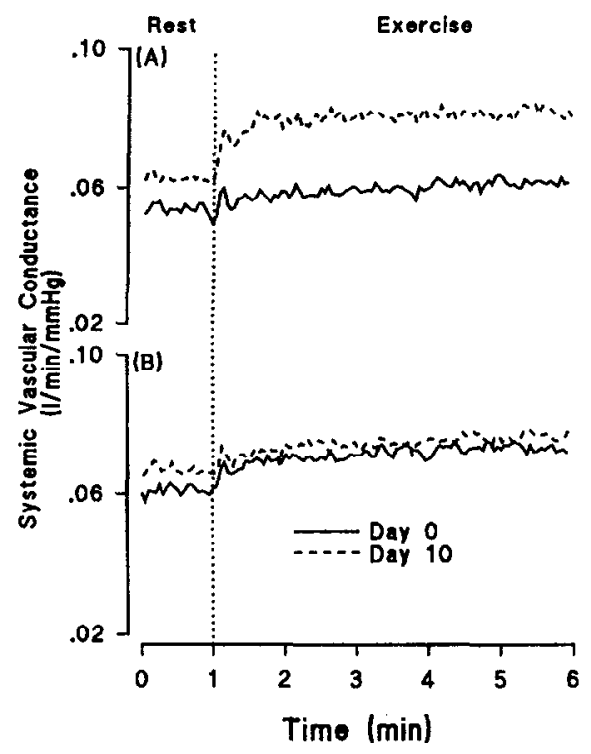

Fig. 2. The amplitude of both cardiac output (left side) and systemic vascular conductance (CO/MAP) (right side) for the endurance-trained group (A) was greater on Day 10 compared with Day 0 whereas no effect of test day was observed in the control group (B). Cardiac output on Day 10 was significantly greater $(P<0.05)$ at a sampled time point $(20 \mathrm{~s})$ and throughout steady-state exercise compared to Day 0 for the trained group. The data represent the average of all endurance-trained or control subjects performing 4 trials each on each test day and the average of three data points is plotted for all responses. 
examine an earlier point in the $\mathrm{CO}$ response. For the ET group, the amplitude of $\mathrm{CO}$ at $20 \mathrm{~s}$ after the onset of exercise was greater $(1.21 \pm 0.42 \mathrm{l} / \mathrm{min})$ in the Day 10 tests compared with Day $0(0.57 \pm 0.621 / \mathrm{min})(P<0.05)$. No difference in $\mathrm{CO}$ at this time point was observed between test days for the $\mathrm{C}$ group.

In the ET group the amplitude of the systemic vascular conductance (CO/MAP) at $5 \mathrm{~min}$ of exercise was greater $(P<0.05)$ on Day $10(0.022 \pm 0.01 \mathrm{l} / \mathrm{min} / \mathrm{mmHg})$ compared with Day $0(0.016 \pm 0.01 \mathrm{l} / \mathrm{min} / \mathrm{mmHg})$. The corresponding values for the $\mathrm{C}$ group were $0.011 \pm 0.01$ and $0.015 \pm 0.01 \mathrm{l} / \mathrm{min} / \mathrm{mmHg}$, respectively $(P>0.05)$.

\subsection{Haematocrit and $\dot{V} O_{2 \text { peak }}$}

Haematocrit was unchanged in both ET and Control groups (Table 1). Peak aerobic power $\left(\dot{\mathrm{V}}_{2 \text { peak }}\right)$ was increased following 10 days of ET (0.05) but was unchanged in C (Table 1).

\section{Discussion}

The major finding of this study was that 10 days of cycle ergometer endurance training increased the rate at which femoral artery $\mathrm{MBV}$ and $\mathrm{VC}_{\mathrm{fa}}$ adapted to a step change in submaximal knee extension (KE) exercise as indicated by $T_{63 \%}$. Training did not affect the levels of either $\mathrm{MBV}$ or $\mathrm{VC}_{\mathrm{fa}}$ at rest or during steady-state exercise but, in agreement with the faster kinetics, the amplitude of the MBV at $10 \mathrm{~s}$ of exercise was greater following training. Training also resulted in greater $\mathrm{CO}$ during the ontransient and steady-state portions of the $\mathrm{KE}$ exercise.

\subsection{Methodology}

The instrumentation used during the execution of this study did not permit determination of the diameter of the femoral artery. Therefore, we were restricted to the use of MBV to characterize the response of blood flow. MBV can predict blood flow only if arterial diameter is unchanged between rest and exercise. This assumption is central to the conclusions of previous investigations of femoral artery blood flow during leg exercise [14-16].

After completion of the training study, access to an ultrasound imaging system (Toshiba Model SSH-140A) allowed us to determine diameters of the common femoral artery in four volunteers during acute knee extension exercise identical to that of the current study. A $5 \mathrm{mHz}$ probe was held over the common femoral artery $2-3 \mathrm{~cm}$ distal to the inguinal ligament and B-mode operations were used to image the vessel. The angle between the scanning head and the vessel was adjusted to $\sim 90^{\circ}$ to optimize the quality of the image. At $10 \mathrm{~s}$ intervals over $1 \mathrm{~min}$ of rest and between 4 and $5 \mathrm{~min}$ of exercise femoral artery diameters were measured. Each of these diameters was the mean of three measures. The results support the assumption of no statistically significant change in conduit arterial diameters during exercise $(9.7 \pm 1.4 \mathrm{~mm})$ compared with rest $(9.5 \pm 1.4 \mathrm{~mm})$ despite the small increase $(\sim 10$ $\mathrm{mmHg}$ ) in arterial pressure. However, it is not known if short-term training affects arterial diameters in humans or whether there might be transient changes in arterial diameter on going from rest to exercise. Consequently, the conclusions of this study are dependent on either no or equivalent changes in vessel diameter in the ET and C groups when going from rest to exercise.

The decrease in MAP from Day 0 to Day 10 in the C group only was unexpected. It is possible that even with familiarization sessions there was some anxiety during the first test.

The measurement of MBV could be subject to a number of methodological problems including probe placement and motion artifact [17]. In addition, the experimental subjects could have become more proficient at doing the exercise. To counter these potential problems, all measurements were made by the same experimenter after a long period of learning to place the probe optimally and to observe the quality of the signal. Having the subjects familiarize themselves with the KE exercise for 2-3 days prior to the commencement of the study also enhanced the quality and repeatability of the measures. Finally, the consistency of the response in the control group gives confidence in the interpretation that there was an effect of exercise training.

Impedance cardiography has been shown to be correlated with other standard methods of $\mathrm{CO}$ determination [11]. In this study, we evaluated both the time course of adaptation of $\mathrm{CO}$ and the magnitude of change during the exercise. The mean response times reported here appear to be slower than those observed previously during two-legged knee extension exercise [14] but are quantitatively similar to measurements during upright cycle ergometry [18]. Eriksen et al. [14] reported simultaneous estimates of aortic and femoral artery blood flow and showed that the $\mathrm{CO}$ response plateaued within $15 \mathrm{~s}$ of the onset of exercise in contrast to the $2 \mathrm{~min}$ or so required in this, and a previous [19], study. It is possible that the supine posture used by Eriksen et al. [14], or differences in exercise mode, caused the differences in CO kinetics.

\subsection{Effects of exercise training}

As indicated in the "Methods", the MBV response incorporated at least two, and sometimes three, phases of increase. Such a blood flow response has been observed previously in humans [14] and dogs [20]. but it has not been quantified and the mechanisms regulating the response have not been formally investigated. Also, the MBV response is only approximated by an exponential model. Therefore, care must be taken when interpreting the results of the curve-fitting procedures to quantify leg MBV 
time courses, particularly when the response is so fast. Nonetheless, it does appear that short-term ET does quicken the $\mathrm{MBV}$ and $\mathrm{VC}_{\mathrm{fa}}$ responses to $\mathrm{KE}$ exercise. An important observation was that the $T_{63 \%}$ of the increase in MBV and $\mathrm{VC}_{\mathrm{fa}}$ was very short, usually occurring within the first component of the response. These data were supported by the observation that the MBV amplitude at $10 \mathrm{~s}$ of exercise was significantly greater following ET.

By the data gathered from the present study it appears that the mechanism(s) which respond to ET producing a faster adaptation of MBV is (are) effective very early in exercise. The blood flow response to exercise is dependent not only on the change in cardiac output, but also on the effect of the muscle pump and various vasoactive metabolites and hormones produced both locally and systemically, all of which affect femoral artery vascular conductance. Some of these may have contributed to the faster adaptation of femoral artery MBV observed here and, as such, the possible contributions of each will be considered.

In writing Ohm's law for the circulation as $\dot{Q}=\Delta P * C$, where $\dot{Q}=$ blood flow, $\Delta P=$ pressure gradient across the vascular bed, and $C=$ conductance $=1 /$ resistance, it is possible to examine both the $\Delta P$ and $C$ contributions. The role of any change in $\Delta P$ is complex. In the present study, there was no significant difference in MAP from Day 0 to Day 10 for the ET group even though the total $\mathrm{CO}$ was increased after 10 days of training. Thus, there was an increase in total conductance to maintain MAP. It is not known if the elevated $\mathrm{CO}$ during the early phase of $\mathrm{KE}$ exercise contributed to, or compensated for, the increase in $\mathrm{VC}_{\mathrm{fa}}$. The latter option suggests that peripheral changes might be involved in the faster MBV kinetics with training. It was also noted that, at $5 \mathrm{~min}$ of exercise, the amplitude of $\mathrm{VC}_{\mathrm{fa}}$ was not different between test days in either the ET or $\mathrm{C}$ groups. Assuming that central venous pressure was the same on each test day, this observation suggests that, with training, vascular conductance through inactive tissue was elevated also.

The pumping action of rhythmically contracting muscle is believed to be a major contributor to the increased vascular conductance with exercise [21]. Evidence from humans [15] and dogs [20] suggests that much of the first component of the increase in blood flow at the onset of exercise is due to the mechanical effects of the muscle pump. Whether or not such a mechanical effect on excrcise blood flow is sensitive to training is not known. However, since the contraction rate, absolute workload, and posture were held constant in this study, it is more likely that other factors are involved in the observed changes to $\mathrm{MBV}$ and $\mathrm{VC}_{\mathrm{fa}}$.

The rapid increase in blood flow with a single contraction has caused investigation into the idea that a neural component is involved in enhancing tissue perfusion. Sympathetic withdrawal to active tissue could result in a rapid increase in perfusion of skeletal muscle. However, neurographic recordings of muscle sympathetic nerve activity during both dynamic [22] and static [23] exercise fail to support this hypothesis. Whether sympathetic effects might be changed by physical training also remains a matter of debate. The vascular smooth muscle response to norepinephrine was reduced in rats which were endurancetrained for 6 weeks [24] although contradictory results were observed in endurance athletes who had undergone prolonged training [25]. These training-induced effects were not measured in the present study. Neurally induced cholinergic vasodilation has also been put forward as a mechanism for the fast adaptation of blood flow in dogs [26], but no such nerves have been found in either primates or humans [27]. Overall, the involvement of a neural component to the rapidly augmented limb blood flow with exercise remains attractive but largely unclear.

Metabolites released from active skeletal muscle are believed to be important in coordinating blood flow with the metabolic demand [28] during exercise. However, this response is believed to be too slow to account for the early phase of vasodilation [28]. Importantly, short-term ET, as used in this study, has been shown to reduce the phosphorylation potential and the production of certain metabolites [29] that have been considered to be vasoactive. These lines of evidence argue against a contribution of metabolites to the faster $\mathrm{MBV}$ and $\mathrm{VC}_{\mathrm{fa}}$ responses. An interesting counter-point to this might be that improved blood flow responses early in exercise could account for the tighter metabolic control observed following short-term training [29].

Endothelial control of vascular smooth muscle tone has been shown to affect vascular diameter within 10-20 s following an increase in blood velocity and shear stress, and to be affected by training. Two important vasodilators produced and secreted by vascular endothelial tissue are nitric oxide [30] and prostaglandins [31]. In rodents, endurance training for 2-12 weeks resulted in a greater dose-dependent vasodilation following topical applications of acetylcholine to isolated arterial strips [3]. These adaptations appear to occur at all levels of the vasculature $[3,24,32,33]$ and their basis has been an increased rate of nitric oxide production by vascular endothelial tissue $[3,24,33]$. Although it has been reported that nitric oxide [34] and prostaglandins [35] are minimally involved in modulating vascular tone in healthy humans during steady-state exercise, more recent evidence demonstrated that infusion of a nitric oxide synthase blocker into the brachial artery of an exercising forearm reduced steadystate blood flow by $20-30 \%$ [36]. It appears, therefore, that the local release of these autacoids can modulate exercise blood flow, but their role during the non-steady states of exercise onset or recovery has yet to be investigated.

The augmented maximal vasodilatory capacity of peripheral vasculature following prolonged endurance training has been attributed to morphological changes [37]. To date, there has been no evidence presented for changes in 
capillary density within the 10-day training period investigated in the current study. If the observed adaptation to MBV kinetics was due to either functional or morphological changes in arterial diameter, then the observed velocities would relate to larger blood flows than expected.

In summary, we have demonstrated that 10 days of endurance training resulted in faster femoral artery MBV and vascular conductance responses following a step increase in work rate. These data supported the hypothesis that endurance training resulted in a faster adaptation of blood flow to exercising muscle, and further showed that this response occurred early in the training program. This change in blood flow dynamics has important physiological implications for both the peripheral and central mechanisms involved in mediating the vascular response and for the metabolic consequences of increased perfusion and oxygen delivery at the onset of exercise.

\section{Acknowledgements}

We gratefully acknowledge the expert technical assistance of S. Grant, M. MacDonald and D. Northey. This study was supported by grants to R.L.H. and H.J.G. from the Natural Sciences and Engineering Research Council of Canada.

\section{References}

[1] Bevegard BS. Studies on the regulation of the circulation in man. Acta Physiol Scand 1963; 200(suppl):1-36.

[2] Andersen P, Henriksson J. Capillary supply of the quadriceps femoris muscle of man: Adaptive response to exercise. J Physiol 1977; 270:677-690.

[3] Sun D, Huang A, Koller A, et al. Short-term daily exercise activity enhances endothelial NO synthesis in skeletal muscle arterioles of rats. J Appl Physiol 1994; 76:2241-2247.

[4] Green HJ, Jones LL, Painter DC. Effects of short-term training on cardiac function during prolonged exercise. Med Sci Sports Exerc 1990;22:488-493.

[5] Hickson RC, Bomze HA, Holloszy JO. Faster adjustment of $\mathrm{O}_{2}$ uptake to the energy requirement of exercise in the trained state. $J$ Appl Physiol 1978;44:877-881.

[6] Guldvog I, Kjaemes M, Thoresen M, et al. Blood flow in arteries determined transcutaneously by an ultrasonic Doppler velocitymeter as compared to electromagnetic measurements on the exposed vessels. Acta Physiol Scand 1980;109:211-216.

[7] Walloe $\mathrm{L}$, Wesche J. Time course and magnitude of blood flow changes in the human quadriceps muscles during and following rhythmic exercise. J Physiol 1988;405:257-273.

[8] Micco AJ (Inventor). CW and Pulse Doppler Diagnostic System. U.S. Patent 4,819,622. April 22, 1989. Int. Cl. A61B 10/00. US Patent 4,819,652 22 April 1989;

[9] Imholz BPM, Settels JJ, van der Meiracker AH, et al. Non-invasive continuous finger blood pressure measurement during orthostatic stress compared to intra-arterial pressure. Cardiovasc Res 1990; 24:214-221.

[10] Nichols WW, O'Rourke MF. McDonald's Blood Flow in Arteries, Philadelphia: Lea and Febiger, 1990.
[11] Du Quesnay MC, Stoute GJ, Hughson RL. Cardiac output in exercise by impedance cardiography during breath holding and normal breathing. J Appl Physiol 1987;621:101-107.

[12] Mohapatra SN. Non-invasive Cardiovascular Monitoring by Electrical Impedance Technique, London: Pitman Medical Limited, 1983.

[13] Hughson RL, Sherrill DL, Swanson GD. Kinetics of $\dot{\mathrm{V}}_{2}$ with impulse and step exercise in humans. J Appl Physiol 1988;64:451459.

[14] Eriksen M, Waaler BA, Walloe L, et al. Dynamics and dimensions of cardiac output changes in humans at the onset and at the end of moderate rhythmic exercise. J Physiol 1990;426:423-437.

[15] Leyk D, Essfeld D, Baum K, et al. Early leg blood flow adjustment during dynamic foot plantarflexions in upright and supine body position. Int J Sports Med 1994;15:447-452.

[16] Wesche J. The time course and magnitude of blood flow changes in the human quadriceps muscles following isometric contraction. $\mathrm{J}$ Physiol 1986;377:445-462.

[17] Gill RW. Measurement of blood flow by ultrasound: accuracy and sources of error. Ultrasound Med Biol 1985;11:625-641.

[18] Inman MD, Hughson RL, Weisiger KH, et al. Estimate of mean tissue $\mathrm{O}_{2}$ consumption at onset of exercise in males. J Appl Physiol 1987;63:1578-1585.

[19] Shoemaker JK, Hodge L, Hughson RL. Cardiorespiratory kinetics and femoral artery blood velocity during dynamic knee extension exercise. J Appl Physiol 1994;77:2625-2632.

[20] Sheriff DD, Rowell LB, Scher AM. Is rapid rise in vascular conductance at onset of dynamic exercise due to muscle pump? Am $J$ Physiol 1993;265:H1227-H1234.

[21] Laughlin MH. Skeletal muscle blood flow capacity: role of muscle pump in exercise hyperemia. Am J Physiol 1987;253: H993-H1004.

[22] Victor RG, Seals DR, Mark AL. Differential control of heart rate and sympathetic nerve activity during dynamic exercise. J Clin Invest 1987;79:508-516.

[23] Mitchell JH. Neural control of the circulation during exercise. Med Sci Sports Exerc 1990;22:141-154.

[24] Wiegman DL, Harris PD, Joshua IG, et al. Decreased vascular sensitivity to norepinephrine following exercise training. J Appl Physiol 1981;51:282-287.

[25] Svedenhag J, Martinsson A, Ekblom B, et al. Altered cardiovascular responsiveness to adrenoceptor agonists in endurance-trained men. $\mathrm{J}$ Appl Physiol 1991;70:531-538.

[26] Honig CR. Contributions of nerves and metabolites to exercise vasodilation: a unifying hypothesis. Am J Physiol 1979;236: H705H719.

[27] Burnstock G. Cholinergic and purinergic regulation of blood vessels. In: D Bohr, AP Somlyo, HV Sparks, eds. Handbook of Physiology, Sect. 2, Vol. II: The Cardiovascular System, Bethesda, MD: American Physiological Society, 1980;567-612.

[28] Laughlin MH, Armstrong RB. Rat muscle blood flows as a function of time during prolonged slow treadmill exercise. Am J Physiol 1983;244:H814-H824.

[29] Green HJ, Helyar R, Ball-Bumett M, et al. Metabolic adaptations to training precede changes in muscle mitochondrial capacity. J Appl Physiol 1992;72:484-491.

[30] Ignarro LJ, Buga GM, Wood KS, et al. Endothelium-derived relaxing factor produced and released from artery and vein is nitric oxide. Proc Natl Acad Sci USA 1987;184:9265-9269.

[31] Koller A, Sun D, Kaley G. Role of shear stress and endothelial prostaglandins in flow- and viscosity-induced dilation of arterioles in vitro. Circ Res 1993;72:1276-1284.

[32] Delp MD, McAllister RM, Laughlin MH. Exercise training alters endothelium-dependent vasoreactivity of rat abdominal aorta. J Appl Physiol 1993;75:1354-1363.

[33] Edwards JG, Tipton CM, Matthes RD. Influence of exercise training on reactivity and contractility of arterial strips from hypertensive rats. J Appl Physiol 1985;58:1683-1688.

[34] Wilson JR, Kapoor S. Contribution of endothelium-derived relaxing 
factor to exercise-induced vasodilation in humans. J Appl Physiol 1993;75:2740-2744.

[35] Wilson JR, Kapoor S. Contribution of prostaglandins to exercise-induced vasodilation in humans. Am J Physiol 1993;265: H171-H175.

[36] Dyke CK, Proctor DN, Dietz NM, et al. Role of nitric oxide in exercise hyperemia during prolonged rhythmic handgripping in humans. J Physiol 1995;488:259-265.

[37] Green DJ, Cable NT, Rankin JM, et al. Modification of forearm resistance vessels by exercise training in young men. J Appl Physiol 1994;77:1829-1833. 